\title{
Delineation of seizure onset zone using ictal PET in epilepsia partialis continua
}

\author{
Bliede Van den Broeck • Katrien Jansen • \\ Karolien Goffin
}

Received: 11 April 2014 / Accepted: 18 August 2014 /Published online: 19 September 2014

(C) Springer-Verlag Berlin Heidelberg 2014

A 13-year-old boy, with no relevant medical history, presented with a recent onset of epilepsy. He initially had several generalized seizures which were treated with antiepileptic drugs. He continued having continuous partial epileptic attacks with dyskinesia of the tongue and mouth.

MRI showed hyperintense lesions on fluid-attenuated inversion recovery (FLAIR) images in the left precentral gyrus and medial frontal gyrus (a, yellow arrows). To localize the seizure onset, an ictal brain FDG PET was performed, which showed intense uptake in the left precentral gyrus (b, blue arrow), corresponding with the motor cortex of the tongue and jaw. There was also a focus of high metabolism in the left frontal lobe and the putamen (b, orange arrow) as well as in the right cerebellum (b, red arrow) because of seizure propagation and crossed cerebellar hypermetabolism. There was diffuse hypometabolism in the remaining cortex in the context of a functional deficit zone. Coregistration of the images (c) shows correspondence of the focal hypermetabolism with the hyperintense lesions on FLAIR images. A biopsy of the lesion in the left frontal lobe showed a gangliocytoma. Because of the localization in eloquent cortex, a resection was not possible and treatment started with radiotherapy.

FDG PET is usually used for evaluation of brain metabolism interictally, but during epilepsia partialis continua, ictal FDG PET can be a valuable imaging tool since it can not only

B. Van den Broeck $\cdot$ K. Goffin $(\triangle)$

Department of Nuclear Medicine, University Hospital Leuven,

Herestraat 49, 3000 Leuven, Belgium

e-mail: karolien.goffin@uz.kuleuven.be

\section{K. Jansen}

Department of Pediatrics, University Hospital Leuven, Herestraat 49, 3000 Leuven, Belgium depict the functional deficit zone but also show the ictal onset zone [1-4].

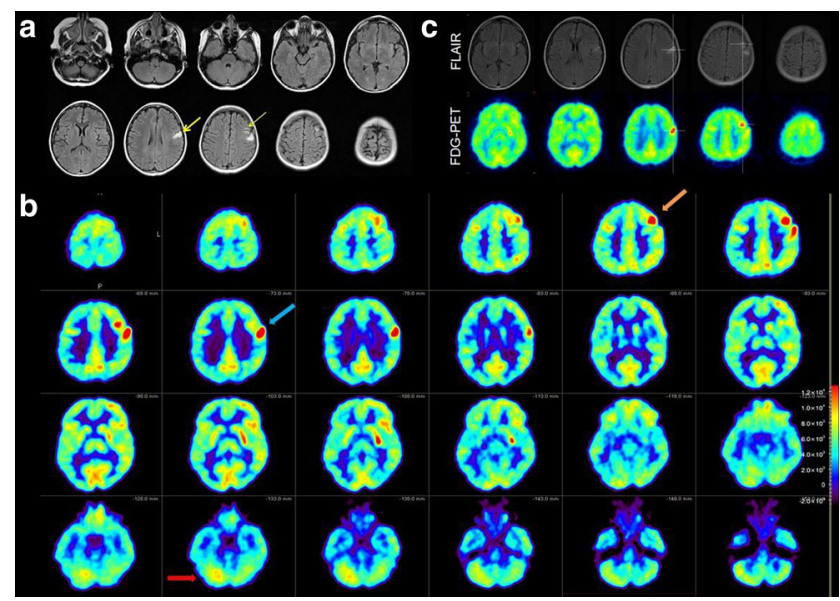

\section{References}

1. Palmini A, Van Paesschen W, Dupont P, Van Laere K, Van Driel G. Status gelasticus after temporal lobectomy: ictal FDG-PET findings and the question of dual pathology involving hypothalamic hamartomas. Epilepsia 2005;46:1313-16.

2. Van Paesschen W, Dupont P, Sunaert S, Goffin K, Van Laere K. The use of SPECT and PET in routine clinical practice in epilepsy. Curr Opin Neurol 2007;20:194-202.

3. Meltzer C, Adelson P, Brenner R, Crumrine P, Van Cott A, Schiff D, et al. Planned ictal FDG PET imaging for localization of extratemporal epileptic foci. Epilepsia 2000;41:193-200.

4. Siclari F, Prior JO, Rossetti AO. Ictal cerebral positron emission tomography (PET) in focal status epilepticus. Epilepsy Res 2013;105:356-61. 